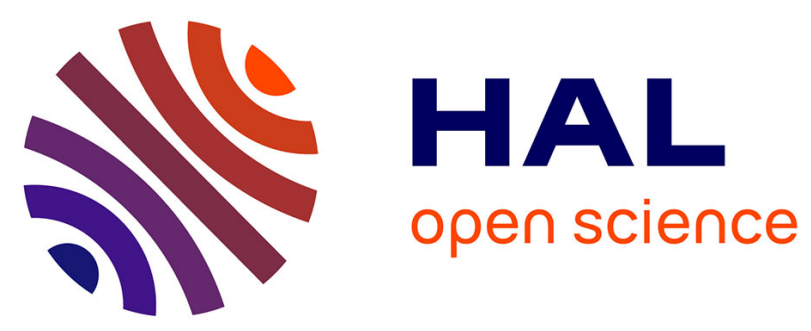

\title{
I do it my way: Understanding policy variation in pandemic response across Europe
}

Clara Egger, Raul Magni Berton, Sebastian Roché, Kees Aarts

\section{To cite this version:}

Clara Egger, Raul Magni Berton, Sebastian Roché, Kees Aarts. I do it my way: Understanding policy variation in pandemic response across Europe. Frontiers in Political Science, 2021, 3, pp.62069. 10.3389/fpos.2021.622069 . halshs-03141146

\section{HAL Id: halshs-03141146 \\ https://shs.hal.science/halshs-03141146}

Submitted on 3 Jan 2022

HAL is a multi-disciplinary open access archive for the deposit and dissemination of scientific research documents, whether they are published or not. The documents may come from teaching and research institutions in France or abroad, or from public or private research centers.
L'archive ouverte pluridisciplinaire HAL, est destinée au dépôt et à la diffusion de documents scientifiques de niveau recherche, publiés ou non, émanant des établissements d'enseignement et de recherche français ou étrangers, des laboratoires publics ou privés. 


\section{University of Groningen}

\section{I do it my way}

Egger, Clara; Magni Berton, Raul; Roché, Sébastian; Aarts, C.W.A.M.

Published in:

Frontiers in Political Science

DOI:

10.3389/fpos.2021.622069

IMPORTANT NOTE: You are advised to consult the publisher's version (publisher's PDF) if you wish to cite from it. Please check the document version below.

Document Version

Publisher's PDF, also known as Version of record

Publication date:

2021

Link to publication in University of Groningen/UMCG research database

Citation for published version (APA):

Egger, C., Magni Berton, R., Roché, S., \& Aarts, C. W. A. M. (2021). I do it my way: Understanding policy variation in pandemic response across Europe. Frontiers in Political Science, 3, [622069]. https://doi.org/10.3389/fpos.2021.622069

\section{Copyright}

Other than for strictly personal use, it is not permitted to download or to forward/distribute the text or part of it without the consent of the author(s) and/or copyright holder(s), unless the work is under an open content license (like Creative Commons).

The publication may also be distributed here under the terms of Article $25 f a$ of the Dutch Copyright Act, indicated by the "Taverne" license. More information can be found on the University of Groningen website: https://www.rug.nl/library/open-access/self-archiving-pure/taverneamendment.

Take-down policy

If you believe that this document breaches copyright please contact us providing details, and we will remove access to the work immediately and investigate your claim.

Downloaded from the University of Groningen/UMCG research database (Pure): http://www.rug.nl/research/portal. For technical reasons the number of authors shown on this cover page is limited to 10 maximum. 


\section{OPEN ACCESS}

Edited by:

Dario Quattromani,

Università Link Campus, Italy

Reviewed by:

Christian Kaunert,

University of South Wales,

United Kingdom

Johan Adriaensen,

Maastricht University, Netherlands

*Correspondence:

Clara Marie Egger c.m.egger@rug.n

Specialty section:

This article was submitted to

Comparative Governance,

a section of the journal

Frontiers in Political Science

Received: 27 October 2020 Accepted: 09 February 2021

Published: 12 April 2021

Citation:

Egger CM, Magni-Berton R, Roché S and Aarts K (2021) I Do it My Way:

Understanding Policy Variation in Pandemic Response Across Europe.

Front. Polit. Sci. 3:622069.

doi: 10.3389/fpos.2021.622069

\title{
I Do it My Way: Understanding Policy Variation in Pandemic Response Across Europe
}

\author{
Clara Marie Egger ${ }^{1 *}$, Raul Magni-Berton ${ }^{2,3,4}$, Sebastian Roché ${ }^{2,3,4}$ and Kees Aarts ${ }^{5}$ \\ ${ }^{1}$ International Relations and International Organization, Faculty of Arts, University of Groningen, Groningen, Netherlands, \\ ${ }^{2}$ Université Grenoble Alpes, Saint Martin d'Hères, France, ${ }^{3}$ Sciences Po Grenoble, Université Grenoble Alpes, Saint Martin \\ d'Hères, France, ${ }^{4}$ UMR5194 PACTE, Grenoble, France, ${ }^{5}$ Faculty of Behavioural and Social Sciences Political Institutions and \\ Behavior, Department Sociology, University of Groningen, Groningen, Netherlands
}

To contain the spread of the COVID-19, governments have designed and implemented a large range of exceptional measures. Yet, the restrictive nature of the policy options chosen and the severity of their enforcement mechanisms considerably vary across countries. Focusing on the case of the European Union - a group of closely connected nations which develop some forms of supranational policy coordination to manage the pandemic-, we first map the diversity of policy responses taken using two original indicators: the stringency and scope of freedom limitations and the depth of control used in their enforcement. Second, we elaborate three theoretical scenarios to explain cross-national variation in pandemic policy-making. Our exploratory results - based on bivariate statistical associations-reveal that structural determinants (the level of political and interpersonal trust, a country's overall resources, democratic experience and, to a lesser extent, political check and balances) shape crisis policy-making more than crisis-related factors such as the magnitude of the crisis at stake. These results call for further research into the determinants of crisis policymaking that we propose to address with a new research project focusing on the modalities, determinants and impacts of exceptional decision making in times of COVID-19.

Keywords: COVID-19, exceptionalism, policy making, crisis mangement, trust

\section{INTRODUCTION}

The COVID-19 pandemic has led governments all over the world to take multiple and diverse policy responses to contain the lethality of the virus. After Asia, Europe was the second continent struck with the first cases of contagion recorded in Italy on January 31, 2020 (Ritchie, 2020). On March 13th, the number of cases in Europe exceeded that in Asia, prompting the World Health Organization (WHO) to declare Europe as the epicenter of the crisis with $40 \%$ of the global cases and $68 \%$ of the deaths (WHO, 2020). With the notable exception of Italy and Spain where the number of cases respectively peaked on March 22nd and on March 27th, European countries were quasi simultaneously affected by the COVID-19 disease. France, Germany, the Netherlands and the United Kingdom reached their peak in the first 20 days of April 2020 (Dong et al., 2020). In less than two months, several European governments were overwhelmed by the expansion of the pandemic. Contrary to their Asian counterparts, European decision-makers had little recent experience of coronavirus-induced respiratory infections. The last serious influenza pandemic dated back from 1968 and affected European countries mostly unequally (Viboud et al., 2005). In addition, at the end of January 2020, little scientific evidence was available on the virus while in March 2020 expert advices were highly 
conflicting. The spread of the virus among children, its airborne nature, the mechanisms of immunity and their duration were among the most notable known unknowns.

This situation places decision-makers in government and politics in high uncertainty (Capano et al., 2020). Faced with such uncertainty, we could have expected European decision-makers to develop at least some similar protocols especially as the European Union (EU) offers coordination mechanisms in public health that go beyond the general guidelines of the WHO. In particular, the adoption in 2014 of the EU Agenda on Health Systems precisely aims at strengthening the resilience of European public health systems to crises (European Commission, 2020b). In addition, joint crisis-management mechanisms-through the EU civil protection instrument-are long established among European countries (European Commission, 2020a). Nevertheless, governments reacted to the pandemic in multiple and sometimes contrasted ways-and continued to do so well into autumn 2020. For example, whereas France implemented one of the toughest lockdowns in Europe, Sweden relied on no lockdown at all to manage the pandemic. As a result, the cross-national variation in COVID-19 policy responses in Europe is very high. Policy responses regulating individual behavior in the wake of the COVID-19 crisis vary along two dimensions: a) the types and scope of the crisismanagement policy tools chosen and b) their enforcement modalities. The types of policy tools refer to the various legal codification of the strategies used by policy-makers to limit the spread of the pandemic (mask wearing, closures of workplaces, schools, restaurants, restrictions of liberties,...) while enforcement strategies rely on different agents using various levels of coercion (increasing police powers, creating new verifications tools, amount of fines, prison sentences, deployment of the military. ..).

The diversity of policy responses of closely connected nations on one continent, which have various forms of crisismanagement coordination mechanisms and are facing the same crisis suggests that domestic specificities have largely led decision-makers to "do it their way." To capture this diversity, empirical research has already been initiated on governments' responses to the COVID-19 pandemic (Hale et al., 2020a; Cheng et al., 2020; Desvars-Larrive et al., 2020). Nevertheless we still know very little about the determinants of cross-national variation in policy-making in time of Sars-CoV-2 pandemic. So far, all existing studies are of a descriptive scope and give preference to the collecting of a few indicators-e.g., on state of emergency declarations (Bjørnskov and Voigt, 2020) or lockdown approaches (Hale et al., 2020a) - in a large number of countries over an analysis of the diversity of the policy responses.

This paper contributes to political science scholarship on crisis policy-making by unpacking the drivers of cross-national variation in crisis-management policies in European Union countries. Crises-no matter their causes-challenge ordinary policy-making processes and trigger various forms of exceptional policy-making ${ }^{1}$ Yet, existing political science scholarship on crisis

\footnotetext{
${ }^{1}$ We define exceptional policy-making as departing from the legal foundations of governance, both the separation of powers and the limitations of freedoms defined in national constitutions.
}

management primarily focuses on how long-established democracies manage foreign policy crisis but rarely on the management of domestic disasters (Allison and Zelikow, 1971; Janis, 1989; Welch, 1989). When they do so, studies mainly focus on crisis decision-making by assessing styles of emergency leadership but rarely investigate the role structural factors play in shaping policy responses to crisis (see for example, Zhou et al., 2018). In contrast, public health scholarship puts forward models of pandemic management distinguishing between the level of decentralization and coerciveness of health crisis management (Desvars-Larrive et al. 2020: 2). The pandemic hence offers an opportunity to bridge the gap between both fields. Understanding crossnational variation in crisis policy-making in Europe is essential to increase the level of preparedness of European countries not only to future pandemic but also, more largely, to future crises such as climate-induced natural disasters or terror attacks. It is even more important as exceptional measures can durably affect democratic resilience by negatively impacting democratic legitimacy and stability (Posner and Vermeule, 2003).

We contribute to this topical debate by developing an original measure of exceptional policy-making in crisis settings focusing on the types and scope of freedom limitations and on the depth of control used to enforce such limitations. We construct this indicator for the 23 largest EU countries. Focusing on Europe allows to maximize the variance of the policy options and to connect them with a comprehensive set health, economic and political factors likely to shape crisis policy-making. At the same time, because of policy-coordination taking place at the EU level, this case study allows to primarily focus on the domestic drivers of crisis policy-making. To unpack the drivers of cross-national variation, we derive from existing theories three policy-making scenarios likely to explain cross-national variation in the severity and intrusiveness of pandemic policy responses.

Our first scenario conceptualizes crisis policy-making as a trade-off between the magnitude of the sanitary crisis, the pandemic management capacities of a country and the expected degree of people's compliance with the adopted measures. The second scenario argues that policy responses are shaped by the room for (political) manoeuver of policymakers. Implementing stringent policies is difficult in democratic systems as the counter-powers and political opponents can contest the chosen policy option. Finally, the last scenario focuses on policymakers-makers' preferences. These preferences may vary across countries due to different degrees of tolerance with restrictions in the rule of law and civil liberties. Within country variation is shaped by the preferences of the ruling party during the crisis.

Our preliminary assessment of the rationale behind pandemic policy-making reveals that structural factors-the level of political and interpersonal trust, a country's overall resources, and democratic experience and, to a lesser extent, political check and balances-shape crisis policy responses more than situational drivers linked to the magnitude of a crisis or to specific crisismanagement capacities. Compared with these long-term, structural factors, political leaders' ideology hardly influences policy choices. Our exploration of crisis-management 
determinants also allow to identify research and data gaps we intend to fill with the development of a new research project.

"Introduction" section of the paper presents the analytical framework of the research. "The Determinants of Variation in Pandemic Policy-Making" section of the paper presents the analytical framework of the paper. The "Data and Methods" " section presents the research design and data used. "European Pandemic Policy-Making Compared" presents the results while the conclusion discusses their contribution to broader debates on crisis politics and identifies further avenues for research.

\section{THE DETERMINANTS OF VARIATION IN PANDEMIC POLICY-MAKING}

Our analytical model puts forward four key sets of drivers to explain cross-national variation in pandemic policy-making. First, the level of scientific evidence on the pandemic, framing the nature of the policy problem at stake. When the virus struck Europe, the few evidence available confirmed the magnitude of the health threat as the virus was known to spread at an exponential level, with most of the patients showing little to no symptoms (while being contagious) and a unknown rate of elder patients or patients with comorbidities affected with lifethreatening symptoms. Yet, before the launch of national research programs on the COVID-19, this limited scientific evidence was made available to all European countries at the same time and hence should not explain variation in policy-making across countries. Second, the magnitude of the health crisis shapes the level of governmental response as a very acute crisis is likely to trigger more stringent types of policy. Third, crisis policy-making options are influenced by the capacities and resources a government has at its disposal to take action. Fourth, political institutions and culture matter in crisis settings. Institutions operate as a framework making specific set of policies more likely and acceptable than others while the political culture shapes the assumptions policy-makers make on the strategies needed to ensure people's compliance. Figure 1 below displays the key determinants of our analytical framework. In what follows, we expose the mechanism linking each driver to a specific policy response and break them down into testable hypotheses.

The declared objective of crisis policy-making is to protect a state's population and its institutions against the disruptive impacts of crises. In the case of a pandemic, policy responses aim to limit the spread of the virus to avoid a collapse of health systems, which are not equipped to cope with extraordinary public health crises, a situation which would lead to an aggravated death toll. The most certain way of reaching this objective consists in exercising a stringent and multi-faceted control over a population's movement and activities. The likelihood and attractiveness of such extreme policy option depend on the combined influence of the above-mentioned factors. Our conceptual framework argues that policy-makers need to arbitrate between these factors in three types of decisionmaking scenarios: the trade-off, checks and balances and ideological scenarios.
First, the tradeoff scenario assumes that increasing control through multifaceted and stringent crisis-management measures is both politically and morally costly for decision makers. Voters care about their rights and policy-makers do so too. A tradeoff thus exists between protecting people from the pandemic and guaranteeing civil liberties and fundamental rights. On the one hand, too stringent policy responses could trigger protest and jeopardize the election prospects of political leaders in democratic regimes. On the other hand, a failure to act can equally have detrimental consequences on the stability and legitimacy of a political system as well as on the credibility and popularity of decision-makers. According to this scenario, we expect policy-makers to opt for stringent policies when the situation they face does not offer any plausible alternative.

Second, the checks and balances scenario assumes that limiting the impact of the pandemic is the most preeminent political issue decision-makers are interested in. Yet, the crisis offers an opportunity to increase their power, which is, in itself, attractive for all European decision-makers. The key difference lies in their unequal capacity to do so. Some European democracies are better designed than others to prevent the incumbents from unduly increasing their control over society. According to this scenario, the existence and nature of institutional counter-powers are expected to reduce the level of stringency and diversity of the measures.

Last, the ideological scenario assumes that decision-makers do not have similar preferences in terms of crisis management styles. Some favor more stringent options while others prefer to guarantee human rights. The policy responses opted for hence depend either on the political culture of each country or on the political ideology of each government.

These three scenarios lead to the formulation of eight preliminary hypotheses seeking to account for cross-national variation in European policy responses to the Sars-Cov-2 pandemic.

\section{Pandemic Policy Making as a Trade-Off}

The key objective of crisis policy making is to address the disruptive consequences crises have on people, institutions and societies. This impact can be of limited scope or of a high magnitude, posing life threat to a large range of people or endangering the stability of a political regime. In assessing policy options, we argue that policy-makers strive to design policies commensurate to the threat they face. An over-reaction or an under-reaction to a crisis can be damaging, not only for reelection prospects but also for the stability or legitimacy of the political system. The cognitive ability of policy-makers to process data on the nature and evolution of crises however remains an open question in existing literature on crisis management (Wilensky, 1967; Turner, 1978; Kam, 1988). In particular, some authors argue that this ability is particularly low in the case of rapidly-evolving crises-such as a pandemic-(Kehinde, 2014; Staupe-Delgado, 2019). Recent research focusing on the declaration of the state of emergency during the COVID-19 pandemic nuances such statement by showing that the level contamination in a country influences the 


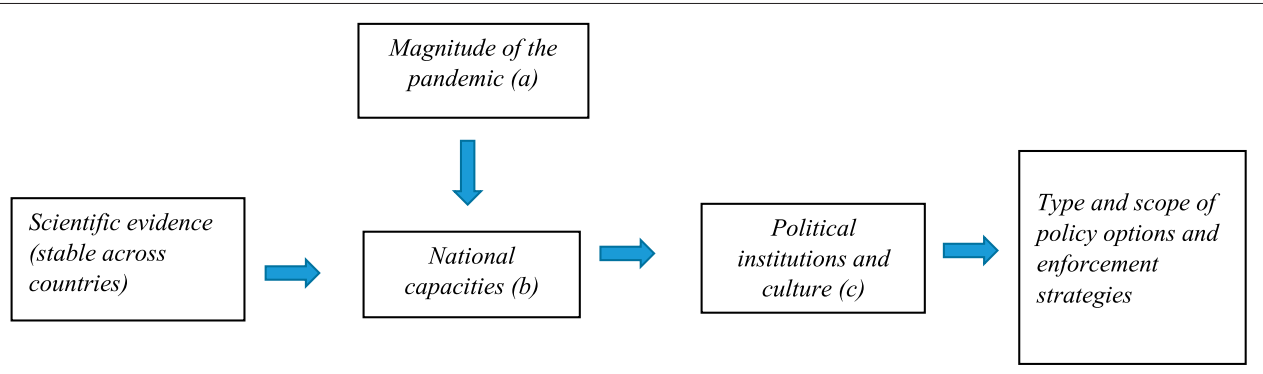

FIGURE 1 | Determinants of variation of pandemic policy-making.

likelihood of a government declaring the state of emergency (Bjørnskov and Voigt, 2020).

As a result:

Hypothesis 1.a: The severity of the pandemic determines the stringency of the policy response.

Faced with a crisis of the same magnitude, policy-makers face different constraints. An extensive literature, both on the current pandemic and other types of crises, stresses the importance of policy capacities in explaining cross-national variation in policy responses (Keman, 2002; Capano et al., 2015; Capano et al., 2020). We argue that such capacities play at two different but interconnected levels. The first refers to the resources allocated to specific crisis-management instruments. In the pandemic case, the magnitude of the crisis mainly derives from the exponential spread of cases, which can rapidly overwhelm the capacities of healthcare systems. As a result, better-equipped health systems are also more able to manage the sanitary crisis without relying on extraordinary measures. For example, the fact that Germany has the highest number of beds in intensive care units per inhabitant has frequently been invoked as an explanation for its resilience to the current pandemic (Schneider et al., 2020). A well-resourced healthcare system allows to identify cases rapidly and to treat the complications in an efficient way. In contrast, weak healthcare systems are more quickly overwhelmed. A high investment in healthcare resources should hence reduce the magnitude of the crisis and the need for stringent policy responses.

Hence:

Hypothesis 1.b: The higher the healthcare resources of a state, the less stringent the policy response chosen.

The second level lies in the overall capacity of a government that allows it to design responses in various range of policy fields but also to allocate new resources to crisis management. This capacity includes the level of resources a country currently has but also its capacity to raise more resources on financial markets through the issuing of national debt. The fact that countries with a low-level indebtedness resist better to crises has already found some support in existing literature (Marto et al., 2018). When the public debt is high, governments lack liquidity to invest in crisis response and provide financial or technological incentives to ensure citizens comply with the measures. An information-based policy style implies that governments are able to invest resources in research but also on public awareness campaigns to make their policies known and understood. In contrast, states lacking capacities can do little but opt for a more authoritarian approach, redirecting their enforcement resources to the management of the crisis.

We hence argue that:

Hypothesis 1.c.: The higher the financial capacity of a state, the less stringent the policy response chosen.

Beside capacities, policy-makers also have expectations on how people will respond to the measures they take. Policymakers make assumptions all the time about whether and to which extent people will comply (Schneider and Ingram, 1990). The higher the expected compliance with government policies, the less coercion is needed to bring about the desired behavior. And policy-makers will avoid coercive mechanisms, which include fines, police force and even imprisonment, whenever they can (De Groot and Schuitema, 2012; Landa and Tyson, 2017). The reason for this is that a widely shared belief in the justness, or legitimacy of these measures is a much stronger driver of political support-not only for the measures in question but also, through spillover processes, for those who designed them (the political authorities) and for the regime (Gibson, 1989; Rothstein, 2012). Compared with a reliance on legitimacy beliefs, relying on coercion to obtain compliance is always at most a second-best option. This current pandemic provides us with an excellent chance to observe these theoretical expectations at work in a real-life setting. It is well established that countries differ with regard to the extent to which their citizens believe in the legitimacy of social institutions, government or democracy. Several southern-European nations such as Spain and Italy show significantly lower levels of trust in the governmental institutions than other countries (van Ham et al., 2017). These differences are also reflected in the extent to which people are satisfied with the way democracy works in their country: the patterns are similar. Finally, countries also differ in the extent to which citizens trust each other. According to several surveys (World and European Values, European Social Survey), notably the Nordic countries can be characterized as "high-trust" whereas in Europe countries like Spain and France show much lower levels of interpersonal trust.

As a result:

Hypothesis 1.d: The higher political legitimacy and interpersonal trust, the less coercive, and stringent the selected policy options can be, since citizens and politicians alike can expect compliance without coercion. 


\section{Pandemic Policy-Making as an Outcome of Domestic Institutional Constraints}

In democratic systems, departing from ordinary policy-making requires the consent of domestic political stakeholders. The nature of the political institutions and the extent of counter powers' controls vary across countries. In particular, a process of policy change -especially of the magnitude required by the management of crises-is more complicated when many veto players are involved. The dispersion of veto players has already been found to generate policy rigidity and a lack of resilience in the case of financial crises (MacIntyre, 2001; Burns et al., 2018). Yet, neither the role of veto players in the management of other types of crises, nor their impact on the types (and not on the mere presence or absence) of policy responses have been researched so far. This neglect is surprising as crises induce risks of power concentration by the executive, leading policy-makers to be appealed by the implementation of more stringent and coercive policies than in non-crisis times. Check and balances should play a central role in making such option more costly for policy-makers.

As a result:

Hypothesis 2.a.: The more the check and balances, the less stringent the policies

In some instances, the control of veto players is not stable throughout the crisis period. Countries that have provisions for forms of emergency decision-making grant veto players a strong role at the beginning of the crisis when authorizing exceptional decision-making. This control then lapses for the limited period of time when emergency provisions are activated. We may then expect the freedom limitations and depth of control of crisis policy responses to be influenced by the existence of emergency decision-making provisions in a country. Such provisions are not uncommon. Today, 90 countries in the world have policy-making mechanisms for emergency situations designed in their national constitution (Bjørnskov and Voigt, 2018a). Such "emergency constitutions" (Idem) allow restrictions in human rights and democratic processes to fight against a crisis. The very existence of such provisions explains why some countries declare state of emergency in the event of crises more often than others (Bjørnskov and Voigt, 2018b). Because emergency constitutions emancipate governments from democratic control, we expect that countries declaring a state of emergency adopt more restrictive and intrusive measures than countries that did not activate such mechanism.

Hence:

Hypothesis 2.b: When a state of emergency is declared, policies are more stringent

\section{Pandemic Policy-Making as Political Ideology}

Beyond political institutions, the political culture of a country determines which types of political practices are deemed tolerable and influence the preferences of political elites. According to the recent history of a country, authoritarian decisions are considered more or less exceptional or acceptable. In countries where political attitudes are more authoritarian, leaders have more leeway in choosing harsher policies. A number of EU countries have experienced a recent transition from authoritarianism to democracy, mainly in the Eastern and Southern part of Europe. Therefore, we can assess whether authoritarian past experiences may lead policy-makers to opt for stringent and coercive decisions since they themselves were socialized in less democratic settings, and since they assume that they would be tolerated by the public. The existence of such a mechanism has already been attested in the case of Southern Europe (Morlino, 2010).

As a result:

Hypothesis 3.a An authoritarian political culture increases the likelihood of stringent and coercive policy responses.

Policy-makers preferences also differ according to the party they belong to. This, in turn, leads political choices to vary according to the political ideology and agenda of the ruling party. When it comes to the rule of law and to fundamental liberties, ideological differences between rulers are rather strong in Europe. The Prime Minister of Hungary Viktor Orban, for example, leads his country in an "illiberal constitutionalism" which could exacerbate freedom limitations in a crisis context. He was, indeed, the only leader in Europe who declared the state of emergency without any time limit (Drinóczi and Bień-Kacała, 2020). In contrast, the prime minister of Sweden Stefan Löfven argued that the government could not ban everything and that individuals will take responsibility for their own health and the health of the community (Bolsover, 2020). Actually, the way governments solve the dilemma between protecting civil liberties and reducing contagion can be influenced by their ideological approach. This is particularly true in situations where there is high uncertainty and no established protocol are in place. Therefore, we expect that the preferences of the ruling party influence the stringency of its policies:

Hypothesis 3.b: Authoritarian parties' ideology increases the likelihood of an aggressive policy response.

Note that the proposed scenarios are not necessarily conflicting with each other. In designing crisis-management policies, policy-makers can assess the level of risks they are able or ready to take (trade off scenario) while selecting among possible options based on their political constraints or ideological preferences. Yet, the proposed scenarios have the merit to comprehensively map the drivers of crisis policy-making.

\section{DATA AND METHODS}

Our research design engages in the preliminary assessment of each scenario. To understand how each of the above-identified factors shapes policy-makers' decisions, we opt for focusing on the initial stage of the pandemic when the first cases were recorded and exponentially grew in Europe. This allows us to consider the highest period of uncertainty and, arguably, the most acute phase of the crisis. Subsequent policy-making does not only build on these initial experiences but also on an expanded evidence base. Our empirical analysis focuses on the types of 
policy responses implemented in 23 European Union countries ${ }^{2}$ that have been quasi simultaneously struck by the COVID-19. The analysis covers the first four months of the spread of the virus on the European continent, from February 1st' 2020 to May 30th.

Overall, 17 countries in our sample have experienced a peak of contagion between March 27 and April 12, hence over a period of only 17 days. The analysis of a limited set of highly interdependent countries allows us to collect detailed data on the measures taken and to control for variation in the geopolitical context and international factors. Compared to other pandemic-affected countries, EU countries engaged in intensive coordination mechanisms at the supranational level. In particular, the European Center for Disease Control issued guidelines and risk assessment reports at the very start of the pandemic and updated them regularly. In addition, the European Council activated the EU integrated political crisis response (IPCR) holding weekly meetings gathering EU institutions, EU agencies experts and representatives of affected member states. At the implementation level, the Union joint civil-protection instrument coordinated the deployment of medical teams and established a common European reserve of emergency medical equipment (European Council, 2020). Despite these early coordination efforts, resources in public health crisis management at the EU level are scarce and mechanisms of a soft nature: EU member states retain primary decision-making powers and capacities in public health matters (Jordana and TriviñoSalazar, 2020). In many ways, the situation of EU countries bear similarity with the one of federal states-such as the United States and Canada -where the federal government mainly holds coordination and information powers while states, at the subnational level, are in charge of designing the policy response they see fit for their context. Lessons learned from the EU context can, to some extent, be applied to other decentralized political contexts.

The observed variation in crisis policy-making in Europe shows that, confronted with an external shock, national public authorities have great latitude in framing the nature of the policy problem at stake and the adequate policy responses. This leads policy-makers to sometimes present the crisis as extreme as when the response to COVID-19 was coined "warfare" by some leaders (Hungary, France) or explicitly rebuffed this expression (the Netherlands, Germany) (Roché et al., 2020). This definition of a situation as an exception does not only occur at the symbolic level when a leader addresses the people, but also on a legal and practical basis. As a result, our dependent variables seek to capture this different level of exceptionalism by especially focusing on two dimensions through which crisis policies are imposed on the public: "freedom limitations" and "depth of control."

Freedom limitations may take different meanings, covering civil rights (equality before the law), political liberties (freedom of speech, of assembly, of conscience), basic rights (such as freedom of movement, to privacy) as well as social rights (right to education) and economic rights (to do business). In tackling

\footnotetext{
${ }^{2} \mathrm{We}$ added the United Kingdom which is still in transition period after the Brexit referendum and excluded $\mathrm{EU}$ countries for which data on independent variables were partial.
}

the threat caused by the COVID-19 crisis, the most radical governments aimed to exercise control over any unapproved interpersonal contact outside households, even preventing family gatherings. For example, some governments such as the French one went as far as prohibiting any family member to attend to funeral while others such as Spain totally confined people in their homes. When, in times of COVID-19, a government decides that being outside one's home is illegal, all types of freedom limitations are at stake although with some forms of national variations: freedom of assembly (no gathering), of movement (limited in several ways), of privacy (with surveillance of allowed movements, use of dedicated applications, searching bags when exiting a department store or on the streets), of social and economic nature (with a shutdown of selected businesses or compulsory work of others). Some limitations such as school closures are means to an end, and not an end in themselves. Yet, in more intrusive forms of policy responses, being on the street becomes a public order issue requiring police action, as if it were a special kind of (one person) illegal protest.

Given the variation in national situations, our first construct "freedoms limitations" needs to incorporate as many dimensions as possible, as well as the geographic scope of the lockdown, which are not available in other constructs such as the Oxford tracker (Hale et al., 2020b). We use for that purpose a combination of two sources of information: the communication on March 26, 2020 by Frontex, the EU agency in charge of external borders security detailing the measures taken in Europe, and press information gathered at EU level. Frontex provides information on restrictions in four aspects of social life: public gathering, school closure, road transportation within the country, and lockdown. Each of these restrictions are coded 0 for open/allowed, 1 for restricted and 2 for closed/banned). In order to account for the geographical scope of the limitations, we decided to integrate into the construct an additional, media-based score which increase the range of the freedom limitations construct: the score increases when a lockdown is implemented "nationally" compared to "locally." We hence multiply the lockdown score by a coefficient of 2 when a government imposes a national lockdown. Raw lockdown score ranges from 0 to 2 before the integration of the geographical score, and from 0 to 4 after, which represents a maximum of 2 additional points in the freedom limitations construct for countries imposing a national lockdown. Theoretically, the freedom limitations score ranges from 0 (no limitation according to Frontex) to 10 (maximum Frontex scores for public gathering, school closure, road transportation (6) and maximum Frontex score on lockdown (2) multiplied by 2 if implemented nationally (4)). A lack of reliable cross-national data prevented us from incorporating limitations imposed on the mobilization of critical citizens and opposition parties.

Figure 2 shows the differences in freedom limitations across EU countries. It reveals that all the countries of our sample implemented some forms of freedom limitations to tackle the pandemic. Yet, the scope of limitations varies from single to double. Sweden and the United Kingdom opted for the less stringent measures-even their leaders refuse the speak of a strategy of an "herd immunity" strategy while Greece scores 


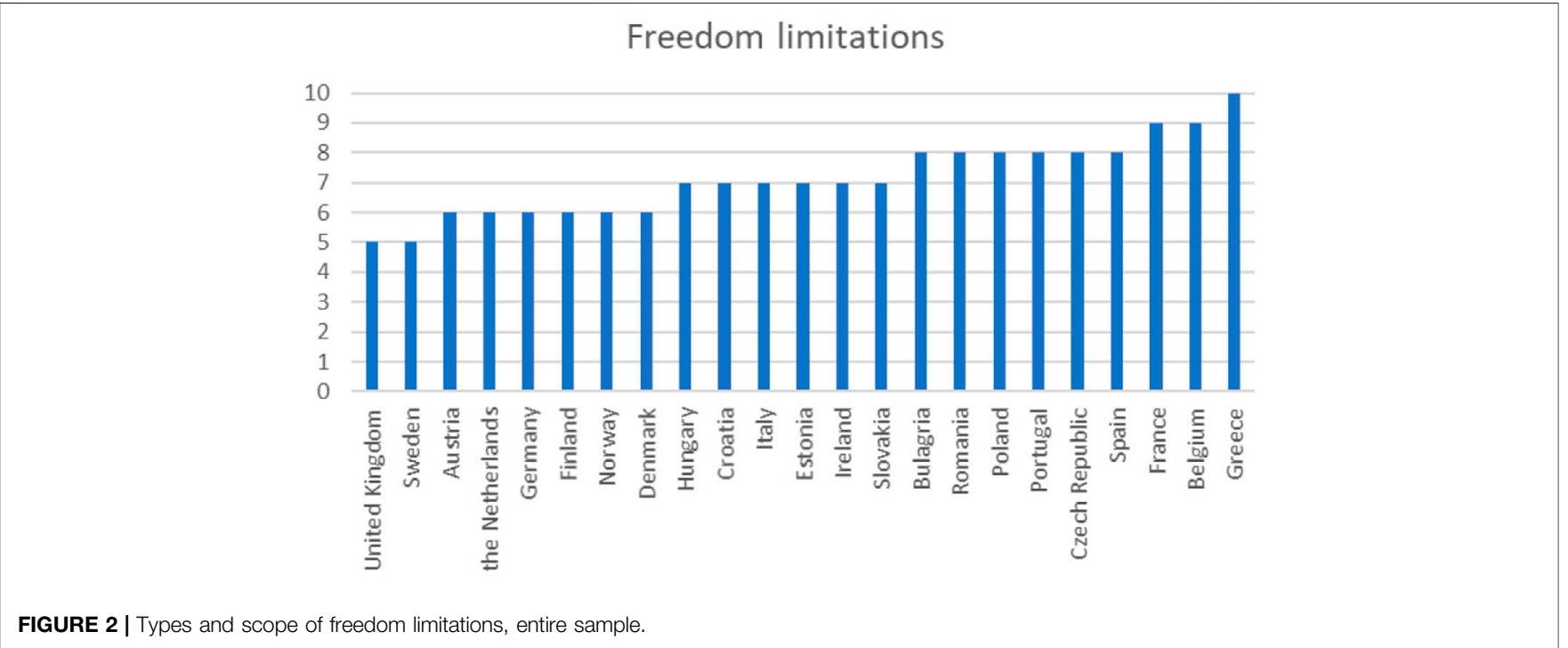

the highest on our index. Surprisingly, France and Belgium score higher (9) than all the Eastern European countries (score 8). Nordic countries-including Germany, the Netherlands but to the exception of Sweden-are situated in a middle ground between the less stringent and the most stringent policy responses.

Relying on the measures decided upon is not enough to fully grasp cross-national variation in crisis policy-making. Each measure -be it a legal or administrative act-allowing to limit freedoms may be enforced more or less coercively. An in-depth control of citizens' behavior will be achieved through two main strategies: creating more legal obligations, and involving more agents with extended powers to ensure citizens compliance. Our second output variable seeks to assess variation in enforcement strategies, adding value to existing data initiatives which only collect information on the decisions taken. Our indicator captures three original dimensions in an additive construct. First, some governments compel citizens to record any movement outside of their home (electronically or with paper and pencil) with a selfestablished declaration. This tool is potentially associated with more fines being distributed as compliance with the regulation can be assessed and sanctioned by the police or any other mandated authority. Such an enforcement authority may go as far as encompassing the police's ability to enter someone's home for check on her presence without any mandate of a judge. Three indicators are used to code such practices. 0 for the absence of such tool, 1 for authorizing police to check the self-declaration for a movement and 2 for police's ability to enter home. Second, the mobilization of enforcement agents may vary across countries. In some cases, the army may be mobilized for non-health-related actions, for example to back up regular police (protecting selected areas) or to serve as a policing force for checking and fining citizens. Here again, three indicators are used coded 0 for no such involvement, 0.5 for military acting as a policing force and 1 for military back up of the police. In other instances, the power to arrest people and sanction them was extended to additional types of non-military and non-police agents which did not have such power prior to the COVID-19, for ex. local or transportation police. We coded this extension 0.5 for the involvement of other forces and 0 in other cases. The depth of control construct does not include the maximum penalty incurred, or the number of fines distributed over the studied period since we could not access this information systematically.

Figure 3 presents variation in enforcement modalities over our sample of countries. It shows that variation at the enforcement level is much higher than at the decision level. In 12 countries, no exceptional tools were used to enforce the policies. However, when exceptional controls are exercised, the level of control considerably varies. Germany used very limited means (0.5) while Bulgaria relied on a large range of strict enforcement mechanisms (4).

Both indicators (freedom limitations, FL and depth of control, DC) are strongly correlated, the Pearson coefficient being 0.60 and significant at conventional standards $(p<0.01)$. However, the correlation can be explained by the fact that, when decisions are the less stringent (low FL score), their enforcement does not rest on highly coercive means (DC null or almost null). In contrast, countries taking more stringent measures (high FL) considerably vary in the enforcement mechanism they use. For example, Belgium and Portugal decided of very stringent restrictions $(\mathrm{FL}=9 / 8)$, yet without relying on exceptionally coercive enforcement means $(D C=0)$. In contrast, Poland or France opted for restrictions of a similar stringency and relied on exceptional means to enforce them $(\mathrm{DC}=3)$.

We use these indicatorss to explore the determinants of restrictive policies in European Union countries. Due to the cross-sectionalism of our data and to our limited number of cases, we are not able to perform any sophisticated statistical analyses. We instead rely on preliminary, bootstrapped bivariate analysis-a method also employed in public health research (Pickett and Wilkinson, 2010)-to assess the association of our output variables with the factors identified in our three policy-making scenarios. The results have to be understood as a general discussion to assess the 
plausibility of each explanation. They also lay the foundation for further research on the modalities and determinants of political exceptionalism in times of crises.

\section{EUROPEAN PANDEMIC POLICY-MAKING COMPARED}

This section highlights the overall congruence of each hypothesis with our data. Before presenting the results of each bivariate analysis, we discuss the operationalization strategy used for each independent variable. Overall, the selection of our indicators builds on past research on crisis and pandemic management but also aims to maximize the relevance and validity of each indicator by comparing how our dependent variable is associated with different measures. Table A1 in Appendix presents the descriptive statistics for all of our variables. We check the robustness of our results by relying on bootstrapping techniques, applied to correlation analysis (Alemayehu and Doksum, 1990).

\section{The Trade off Scenario}

Our first scenario holds that crisis policy responses depend on the severity of the crisis, the crisis-management capacities of a country and the level of compliance policy-makers expect from people. As current research on COVID-19 cases suggests that the reporting of cases highly depends on the quality of the monitoring systems in place at the national level (Lau et al., 2020), we rely on several indicators to analyze the relationship between the magnitude of the public health crisis and the types of policy responses implemented. We use three direct and two indirect indicators. First, building on past research on the determinants of the declaration of state of emergency during the COVID-19 crisis (Bjørnskov and Voigt, 2020), we use the number of positive cases in a country, relying on the dataset published by Our World in Data based on the curated estimates from the European CDC (Ritchie, 2020). As the responsiveness of crisis-management policies varies across EU countries, we first opt for recording the total number of positive cases in each country of our sample over a 30 days period following the first 10 declared cases (contagion). This estimate allows capturing the initial pace of the spread of the pandemic in each country, an indicator likely to reflect the sense of urgency felt by policy-makers as well as the magnitude of the public health threat. Second, we estimate the same indicator but for the number of COVID-19 related deaths, namely the total number of deaths over a 30 days period following the first 10 recorded deaths. It should be noted that the impact of both measures highly depends on the overall population of a country. Our third indicator captures the stress caused by the pandemic on a country health resources; we use the COVID-19-related occupancy of intensive care units (ICU) during the week preceding the adoption of the first restrictions. Although this indicator allows capturing the severity of the pandemic in a reliable manner-as hospitals have specific protocols and testing capacities for COVID-19 patients -, data is missing for half of the countries of our sample.

To indirectly assess the threat posed by the pandemic, we rely on two indicators. The first pertains to the density of the

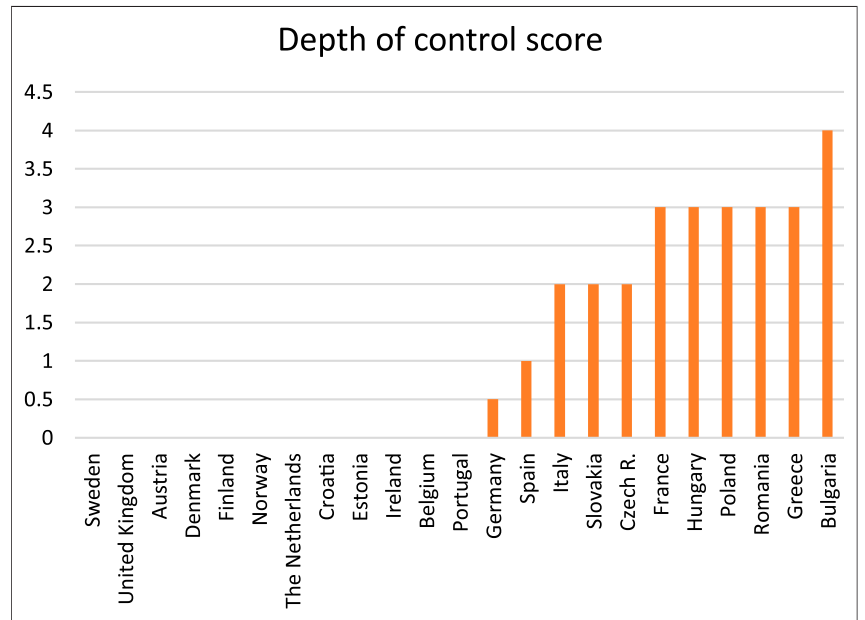

FIGURE 3 | Depth of control in enforcement strategies, entire sample.

population (Ritchie, 2020) as complying with social distancing measures is easier in countries that exhibit a low population density. In contrast, the virus spreads more quickly and easily in densely populated areas. We also take into account that the share of persons at risk of life-threatening complications also varies across countries. To do so, we use the share of people aged 70 (aged_70) as elder people are among the most vulnerable patients.

To the exception of the obvious correlation between the number of deaths and the pace of the contagion, no correlation is observed between our indicators of the severity of the pandemic. Figure 4 exemplifies the results and highlights the relationship between the depth of control and the variable contagion and between Freedom limitations and aged_70. We decided to isolate one commonly used direct indicator and one reflecting the size of the most vulnerable group. Our bivariate analyses also reveal that none of our indicators pertaining to the severity of the pandemic is statistically associated with our dependent variables, the scope of freedom limitations and the depth of control used in enforcing the measures. The absence of statistical relationship stays when each of the bivariate correlation is bootstrapped. This result is surprising as, taken together, our variables capture several dimensions of the severity of the pandemic.

As shown in the Figure 3, the absence of statistical association is not due to specific groups of outliers such as the Scandinavian, Eastern European and Southern European countries.

Our theoretical framework also argues that the type of national policy responses is influenced by the capacity of the healthcare systems. Several indicators are available to assess it, ranging from the level of expenditures in the health sector to the availability of health professionals. Yet, not all of these indicators are relevant to assess the nature of the stress the COVID-19 pandemic poses on health systems.

We select two key indicators likely to capture the specificity of the COVID-19 public health crisis. The first relates to the level of investment in the national health infrastructure. To avoid a spurious correlation with the GDP per capita-richer countries mathematically have higher health budgets than countries with more limited means-we rely on the health expenditure as a 

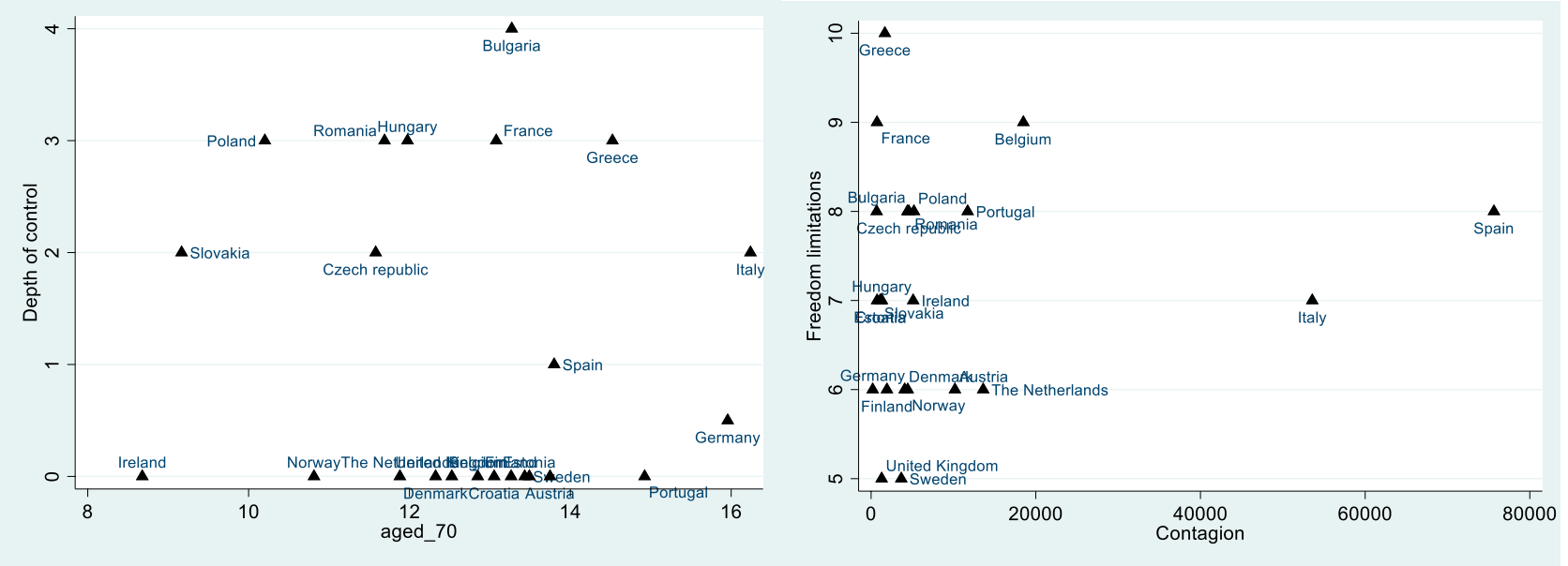

FIGURE 4 | Types of policy responses, contagion and size of vulnerable groups.

share of GDP for 2019 (OECD, 2020). Despite this choice, the variable is still strongly correlated with the GDP per capita $(R=0.57, p<0.01)$ As it assesses the overall health budget, this broad indicator also includes resources spent in sectors that are not central to the management of the COVID-19 pandemic. To compensate for these limitations, we also use a more specific indicator, namely the number of hospital beds per 1,000 inhabitants (beds) (Ritchie, 2020). This enables to capture the specificity of the health crisis triggered by the COVID-19, namely the lack of resources to save the share of people who can become critically ill because of the virus.

Our results only display a correlation between the health expenditure as a share of GDP and the depth of control used in the implementation of the measure (and -0.44 for DC, $p<0.05$ ) which resists in bootstrapped estimates. Countries with larger health budgets adopt less intrusive policy responses but not necessarily less severe ones. Limited health resources hence lead governments to rely more on coercion to limit the stress on their health capacities. More surprisingly, the relationship between the number of beds is statistically associated with DC but goes in the opposite direction $(0.54 p>0.01$ for DC). Figure 5 displays the observed patterns and also sheds light on the distribution of hospital beds in our sample that informs the validity of the relationship observed. Hospital beds are largely available in Eastern countries-which also implemented some of the most stringent policies-but are scarcer in Scandinavian countries, which adopted less restrictive policy responses. This distribution leads to an unexpected correlation and suggests that the availability of the hospital beds is not a relevant indicator to explain cross-national variation in the stringency of crisis-management policy responses. In addition and albeit at the aggregated level, healthcare expenditures are correlated with the measures in the expected direction, many exceptions can be identified. For example, France is characterized by a generous healthcare budget but adopted stringent policies while Ireland implemented less stringent policies despite its limited investment in healthcare.

The overall capacity of crisis-affected states also shapes their policy responses. States with higher resources enjoy an higher room of manoeuver in the design of their policy responses than states with more limited financial means. Following other research on the governmental response to COVID-19 (Bjørnskov and Voigt, 2020), we use the GDP per capita in 2019 (World Bank, 2020), which roughly captures the capacity of the state. Yet, this indicator also captures many other aspects that go well beyond state capacity. High GDP per capita countries are also characterized with higher institutional quality and stronger inter-personal and social trust (Dollar and Kraay, 2003; Butkiewicz and Yanikkaya, 2006). To mitigate such bias, we also assess the relationship between the level of indebtedness of a country (debt \% GDP, Eurostat, 2020, last quarter 2019) and the type of policy responses implemented. Commentaries of the policy responses to COVID-19 in the EU largely reveal how highly indebted countries in the EU were limited in the design of their policy responses due to an incapacity to raise liquidity on financial markets (McMenamin et al., 2020). Although this indicator is more reliable, it also assumes that the management of the pandemic implies a rise of the national debt. This may however not be the case for all countries.

Our preliminary results are ambiguous. The GDP per capita is highly correlated in the expected direction with both FL and DC (respectively, $r=-0.50$ and $-0.65, p<0,01$ ) even when bootstrapped. A positive correlation is only found between $\mathrm{FL}$ and the level of indebtedness $(r=0,47, p<0.05)$ which resists bootstrapping. Figure 6 shows that a low GDP per capita is characterized by more depth of control. However, some countries tend to be too (especially France) or not enough coercive (Croatia, Portugal and Estonia) when their level of wealth is considered. Regarding the relationship between GDP per capita and freedom limitations (not displayed), outliers also exist, such as France, Belgium and Ireland.

Figure 6 also displays the significant association between the level of indebtedness and freedom limitations. However, it shows that Eastern countries tend to increase limitations despite of their relatively low debt. This group of countries further shapes the lack of relationship between the public debt as a share of GDP and the 


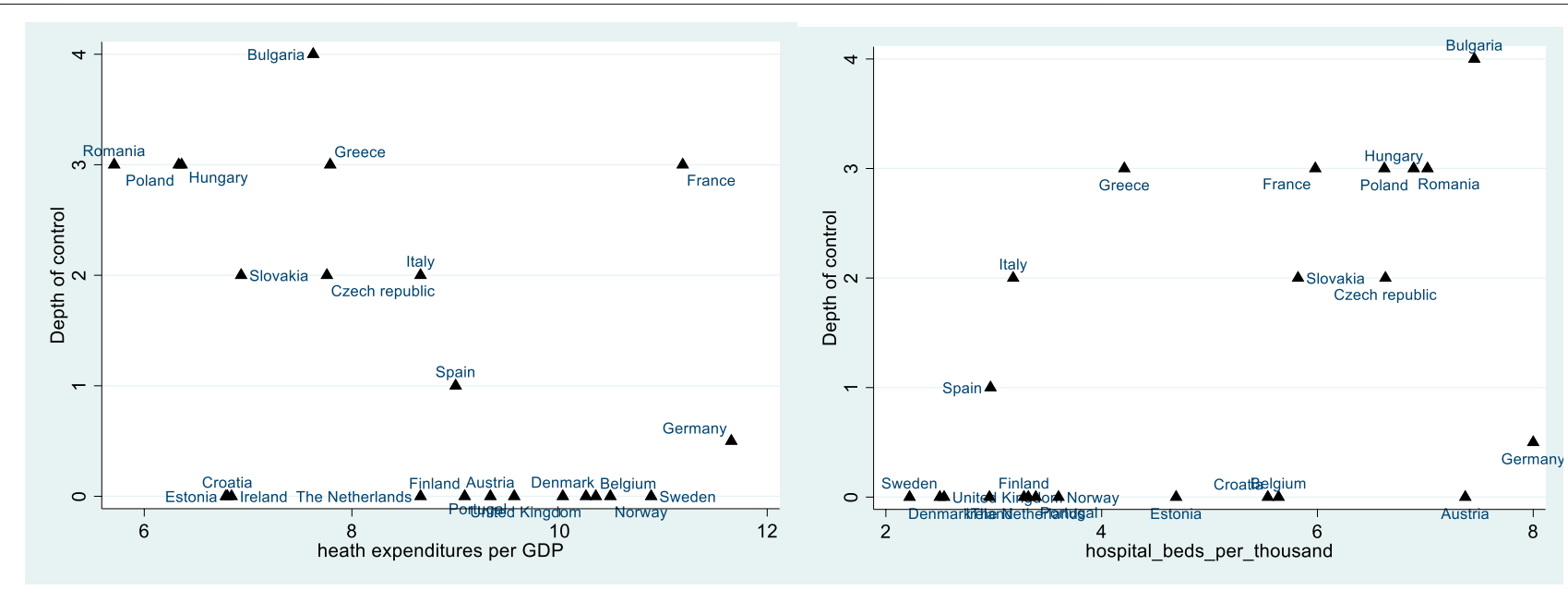

FIGURE 5 | Types of policy responses and capacity of health systems.

depth of control as many it shows that Eastern countries are highly intrusive in the management of the pandemic.

Lastly, we rely on the last wave of the European Values Survey (conducted in 2017 and 2018) to assess the relationship between the level of stringency and coerciveness of policy responses and political and interpersonal trust. Regarding the former, we take into account the fact that most crisis policy-making gives a predominant role to the executive and first use the level of confidence in the government. Second, as the implementation of the measures is mainly left to the police, we also include an assessment of the level of trust in the police. Both indicators vary from $1=$ a great deal of confidence to $4=$ none at all. As the management of the COVID-19 pandemic implies a high degree of compliance by the population, we also include estimates of the level of interpersonal trust, using a question focusing on the degree of confidence respondents have in other people (1. most people can be trusted, 2. you can't be too careful in dealing with people). Finally, the level of satisfaction with the political system $(1=$ not satisfied at all, 10 completely satisfied) is usually associated with trust and compliance (Zmerli et al., 2007).

While these data are not collected just before the sanitary crisis, they have the advantage to be comparative, complete and based on large samples. Data from the last Eurobarometer survey before the pandemic, in November 2019 does not reveal fundamental differences in the trust in government and satisfaction in democracy. However, these more recent data do not include interpersonal trust and trust in police. In addition, trust-related indicators are rather stable over time and a two-year timespan is not enough to trigger visible evolutions in trust rates, especially as no external shock is likely to have affected positively or negatively the level of trust in EU countries.

Even when aggregates are taken into account, these variables are strongly correlated with each other (the Pearson coefficient is between 0.72 and 0.91 ). Yet, each of them captures slightly different dimensions of the propensity to comply with governmental directives. Some capture whether people trust that institutions take right decisions while others capture the importance of pro-social behavior in a community. As we keep the original coding, we expect a negative correlation between the variable of (dis)trust and the measure to limit freedom or the depth of control. In addition, we expect a positive relationship between satisfaction and the output variables.

All the trust-related indicators are significantly correlated in the expected direction with both freedom limitations and depth of control. The highest coefficient is found for interpersonal trust (FL $r=0.70$, DC $r=0.71, p<0.01$ ), followed by regime satisfaction (respectively -0.63 and $-0.58, p<0.01$ ), then trust in police $(0.58$ and $0.61, p<0.01)$ and finally trust in government $(0.66$ and $0.52, p<0.05)$. Note that all these coefficients stay significant when correlations are bootstrapped.

Figure 7 shows the relationship between interpersonal (dis) trust and the output variables. On the one hand, distrust characterizes all the countries that score 7 or higher in freedom limitations while, on the contrary, trust is high in all the countries that score 6 or less. A similar pattern is observed for the depth of control. Only Croatia stands out as combining low levels of interpersonal trust with low levels of controls.

\section{Political Constraints and Pandemic Policy-Making}

Our second scenario argues that policy-makers are constrained by counter-powers when designing crisis policy responses. Yet, the extent of this constraint depends on the institutional set up of each country. In all democratic systems, crisis policy-making gives a central role to the executive. Yet this role is conditioned by the approval of the national parliament. Getting such approval may be more or less easy for governments. To capture the checks and balances exerted by legislative powers in a country, we rely on the level of power-sharing within the parliament. We compute the percentage of seats held by the main party of the ruling coalition perseat) at the beginning of the pandemic updating the data compiled by Teorell et al. (2020). The counter-powers are 


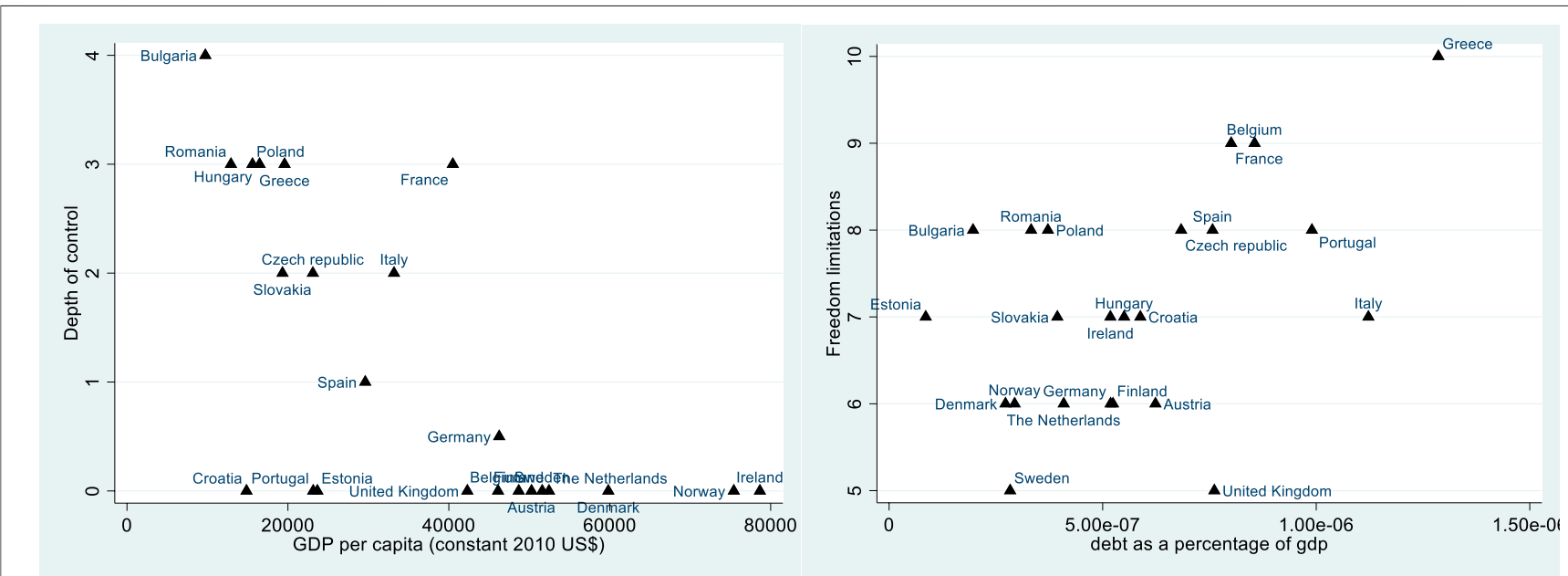

FIGURE 6 | Type of policy responses, GDP per capita and level of indebtedness.
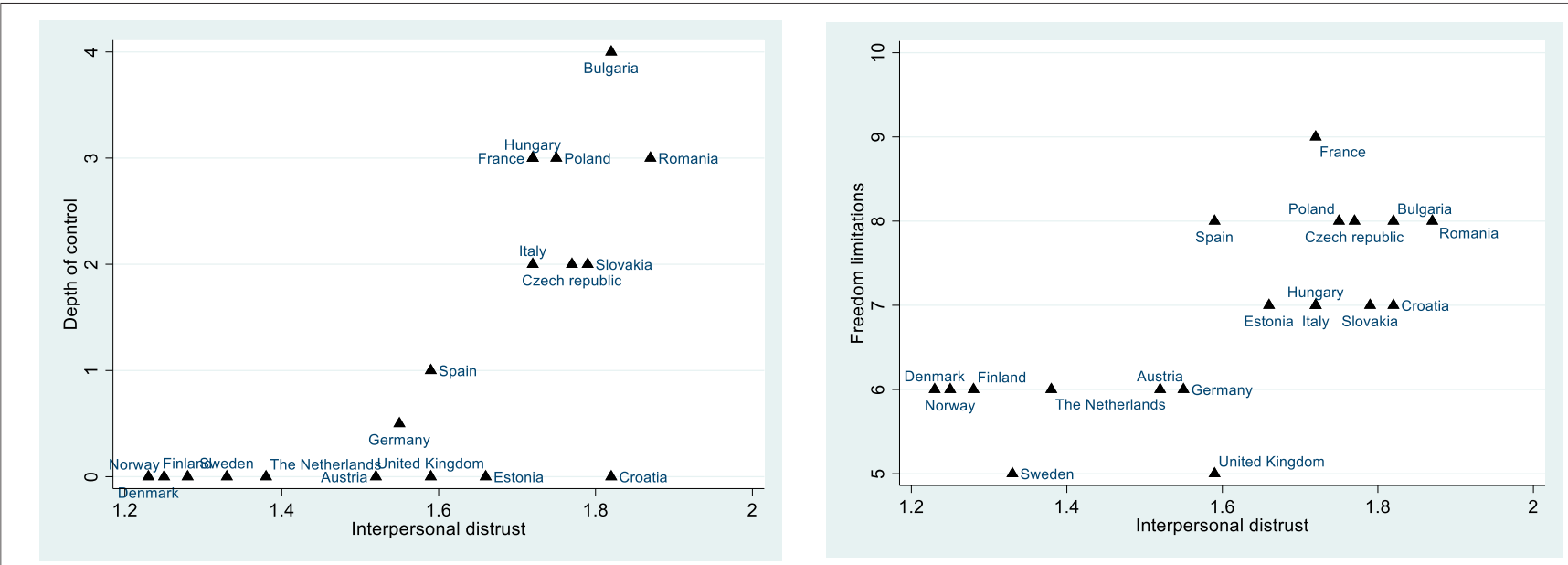

FIGURE 7 | Type of policy responses and interpersonal (dis)trust.

therefore either part of the ruling coalition, or outside of it. We argue that when the main ruling party has a low number of seats in the parliament, it has to seek approval for its exceptional measures from a potentially large set of other represented parties.

Power-sharing is also taking place outside of the parliament and concerns various political institutions such as the judiciary which controls the legality of the measures taken, and subnational entities which have a strong role in health policy-making in decentralized political systems. To capture the role of these diverse political stakeholders, we use a more comprehensive indicator of political constraints (polcon5) the executive has to face in policy-making. It accounts for the veto players of the executive and is structured in an index ranging from 0 to 1 , where 1 is the strongest level of constraints (Henisz and Mansfield, 2006). We use the last release of this commonly used index in comparative political research (see, among others, Freitag and Bühlmann, 2009; Weymouth, 2011) dating from 2017. As with trust indicators, the stability of political institutions over time minimizes the impact of the absence of data for 2019. We expect the percentage of seats held in the parliament by the ruling party to be positively associated with the severity of freedom restrictions and the depth of control while the influence political constraints would be negative.

Both indicators are significantly correlated in the expected direction with the DC (\%seats, $r=0.51$, Polcon5, $r=-0.45$, $p<0.05$ ), but not with FL, even after bootstrapping This is surprising when we take into account that, on the one hand, $\%$ seats and Polcon5 are not correlated with each other $(r=$ $0.07, p>0.7)$ and, on the other hand, DC and FL are highly correlated.

Figure 8 sheds further light on results related to DC. Among the five countries with the highest number of seats for the ruling party $(>50 \%)$, four exert a particularly strong control particularly on their population (scores 3 or 4). Only the United Kingdom did not implement exceptional control, even if the ruling government was widely supported in the 


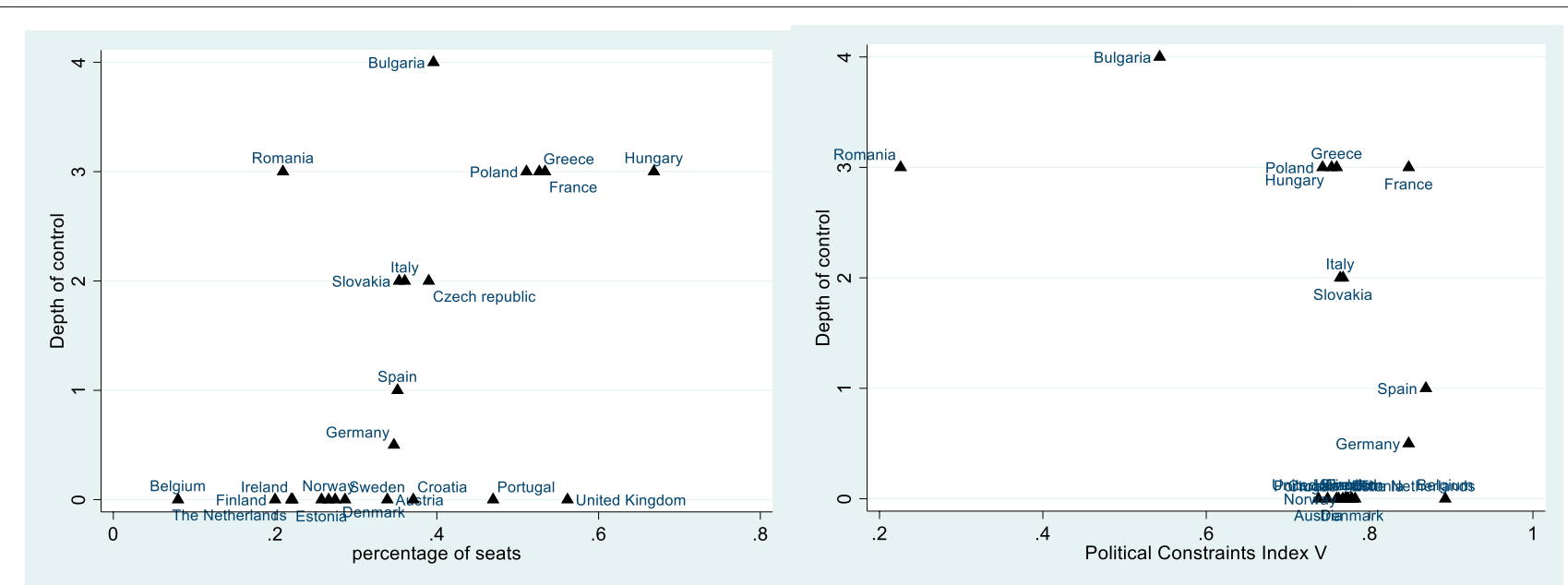

FIGURE 8 | Depth of controland checks and balances

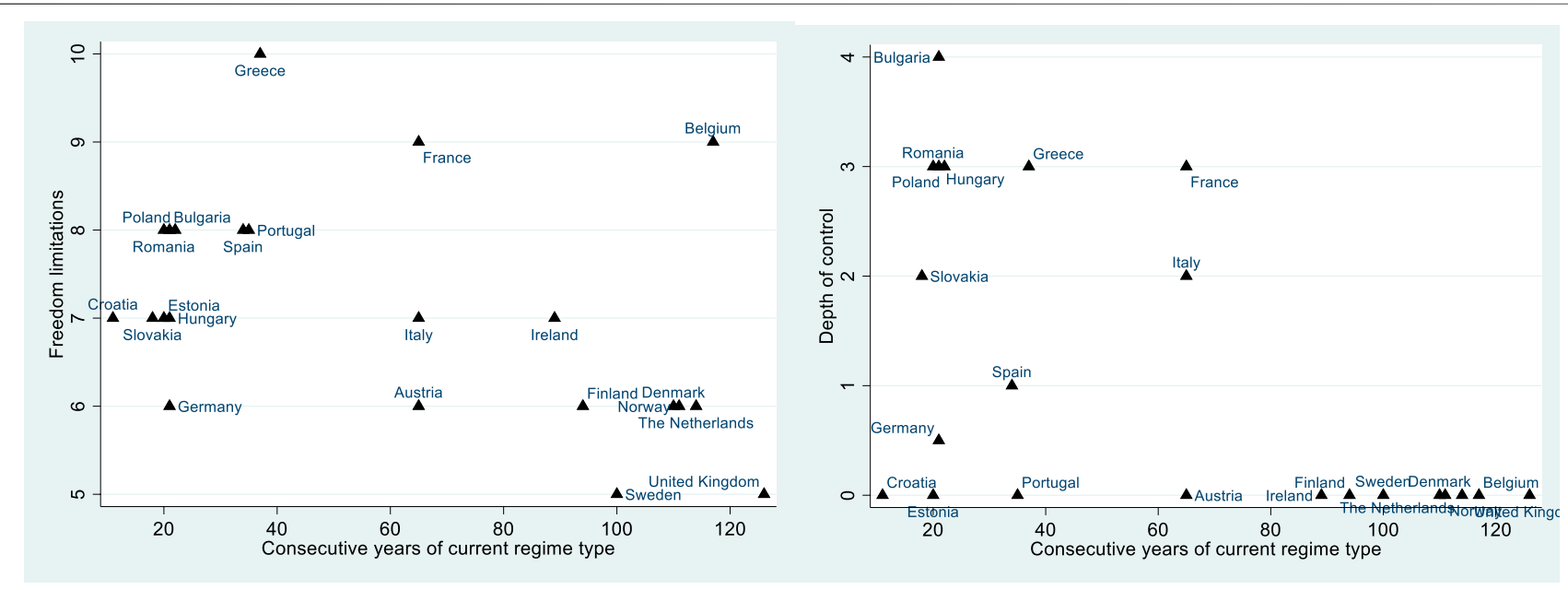

FIGURE 9 | Types of policy responses and authoritarian culture.

parliament. On the other hand, among the nine countries where the leading party in the government holds few seats $(<30 \%)$, only Romania controls citizens more intensively than before the pandemic. When using polcon5, the relationship is less obvious and strongly shaped by two outliers: Bulgaria and Romania that have particularly low counter powers and rely on very intrusive enforcement mechanisms.

While similar patterns hold for the association between these variables and freedom limitations, some slight differences explain changes in the coefficients and their significance. Regarding the perseat variable, Belgium is the country that weighs the most on the overall results, as it has the weakest government, no exceptional control over residents' behavior, but high levels of freedom limitation. Belgium also influences the relationship between polcon 5 and freedom limitations, though to a lesser extent.
We also record all the governments which declare a state of emergency based on media sources and computed a dummy variable state of emergency that identifies the 13 countries that have called a state of emergency. Although the procedure for such a declaration varies across countries, once approved, a state of emergency grants additional discretionary powers to the executive allowing the curtailing of freedom to manage an extraordinary crisis. Unlike the other indicators of check and balances, having declared a state of emergency is correlated with FL $(r=0.37, p<0.1)$, but not with DC. The bootstrapping of the correlation confirms the positive, significant relationship with FL and leads the correlation between DC and state of emergency to reach the $10 \%$ significance level.

The correlation with FL is not surprising since in many systems, declaring a state of emergency is a necessary 
condition to restrict individual rights. However, this does not necessarily mean that enforcement powers are made more intrusive. Note that this result is likely to be due to the fact that five countries (Belgium, Denmark, Estonia, Finland, and Portugal) did not exercise a stronger control on their citizens after declaring a state of emergency while Greece and Poland did so but without relying on a state of emergency. This explains the relative instability of the relationship between the declaration of a state of emergency and the depth of control.

\section{The Ideological Scenario}

Political culture encompasses a large set of different attitudes, beliefs and preferences related to a political process that gives to this concept a rather fuzzy nature (Welch, 2016). Our analytical framework is especially concerned with a specific set of attitudes, namely the tolerance for authoritarian rule that varies across countries. We proxy these attitudes by collecting data on the political past of a country. Our argument claims that countries that have experienced authoritarian rule in their recent past are more prone to relapse into it when faced with a crisis.

We hence count the consecutive years of current regime type (based on Boix et al., 2012) to capture the consecutive years spent under the current regime $(\mathrm{CYCR}$, ranging from Croatia $=21$ years to the United Kingdom $=136$ years $)$. We also updated, in the same database, the past democratic breakdowns (PDB) variable. This variable takes into account all the democratic history and shows little variation across our sample, since only eight countries have experienced a democratic breakdown and only two have done so more than once (France and Greece). The variables are not correlated with each other $(r=-0.3, p>0.1)$.

Both variables are correlated with $\mathrm{FL}$ in the expected direction (CYCR $r=-0.43 p<0.05$, PDB $r=0,63 p>0.01$ ). Only CYRC is significantly correlated with DC $(r=-0.56, p<0.01)$, while PDB slightly exceeds the conventional $10 \%$ level $(r=0.36, p=0.11)$. These results hold when bootstrapping techniques are applied.

Figure 9 shows that the CYCR is associated with depth of control because it isolates the Northern European countries that both are long-established, stable democracies and did not increase the depth of control during the pandemic. However, when these countries are left aside, no correlation is observed. Regarding freedom limitations, Northern countries are also gathered at the bottom right of the graph (a group also including Belgium) and the Eastern countries are together at the top left. As expected, the number of past democratic breakdowns is correlated with both dependent variables essentially because France and Greece have known more than one breakdown in their history and practiced highly restrictive policies.

Last, we focus on the ideological drivers of policy responses. Yet, to capture the ideology of the main party in power, ideological families are not very helpful. For instance, being labeled as communist does not refer to the same tradition and attitudes in Western than in Eastern Europe. The same applies for nationalists or conservatives. To avoid this problem we use the data from the Manifesto Project that provides parties' policy positions derived from a content analysis of parties' electoral manifestos (Krause et al., 2020) in the last national election. We select six topics: 1. Freedom (Favorable mentions of importance of personal freedom), 2. Human Rights (Favorable mentions of importance of human and civil rights), 3. Democracy (Favorable mentions of democracy minus the statements against the idea of democracy), 4. Authority (Favorable mentions of the desirability of a strong and/or stable government), 5. Order (Favorable mentions of strict law enforcement minus rejections of plans for stronger law enforcement), and 6. Military (sentences promoting military minus sentences criticizing military). The three first scores are expected to decrease restrictions and control, the last three to increase them. Pearson coefficients do not display significant coefficients, except for the association between democracy and FL. However, the relationship goes in the opposite direction: when the incumbent party has promoted democracy in the latter election, it also implements more stringent restrictions to face the COVID-19 pandemic (FL $r=0.52 p>0.01$ ).

When bootstrapping techniques are used, results are more congruent with expectations. Freedom becomes negatively associated with FL $(r=-0.31, p<0.05)$ and human rights negatively associated with DC $(r=-0.30, p<0.05)$. This suggests that our results are highly influenced by the presence of outliers in our sample, that Figure 10 below also reveals. First of all, a greater emphasis on human rights appears to lessen the depth of control over individuals. However, one notable outlier also stands out: the Spanish Socialist Party exerted a relatively low control ( 1 out of 4 ) after having strongly campaigned for human rights. Without Spain, however, the correlation stay significant and negative, as expected by our theoretical framework. In particular, when human rights are salient in manifestos $(>1)$ the depth of control is low, while in the five countries that exerted more control over residents, no one is ruled by a party which made this issue salient during its electoral campaign.

Regarding the relationship between the defense of freedom in manifestos and the stringency of freedom limitations, Figure $\mathbf{1 0}$ shows that the Austrian government led by the Austrian People's Party (ÖVP) disproportionately campaigned in favor of individual freedom and, coherently, implemented few limitations. Many countries follow a similar yet less extreme pattern (Norway, the Netherlands, United Kingdom, and Germany). In contrast, the Greek New Democracy's manifesto does not consider freedom as a salient political issue indeed considerably restricted them in pandemic times. This relationship however remains unstable due to many counterexamples such as the French majority party, En Marche! which promoted freedom and greatly limited it faced with the crisis or the Danish Social Democrats, which did not predominantly campaign on freedom, but nonetheless protected them.

\section{DISCUSSION AND CONCLUSION}

Although preliminary-and limited by our sample size-our results shed new light on crisis policy-making and open further avenues for research. As Table 1-summarizing the results of our analysis-shows, none of the three identified scenarios are clearly supported. 


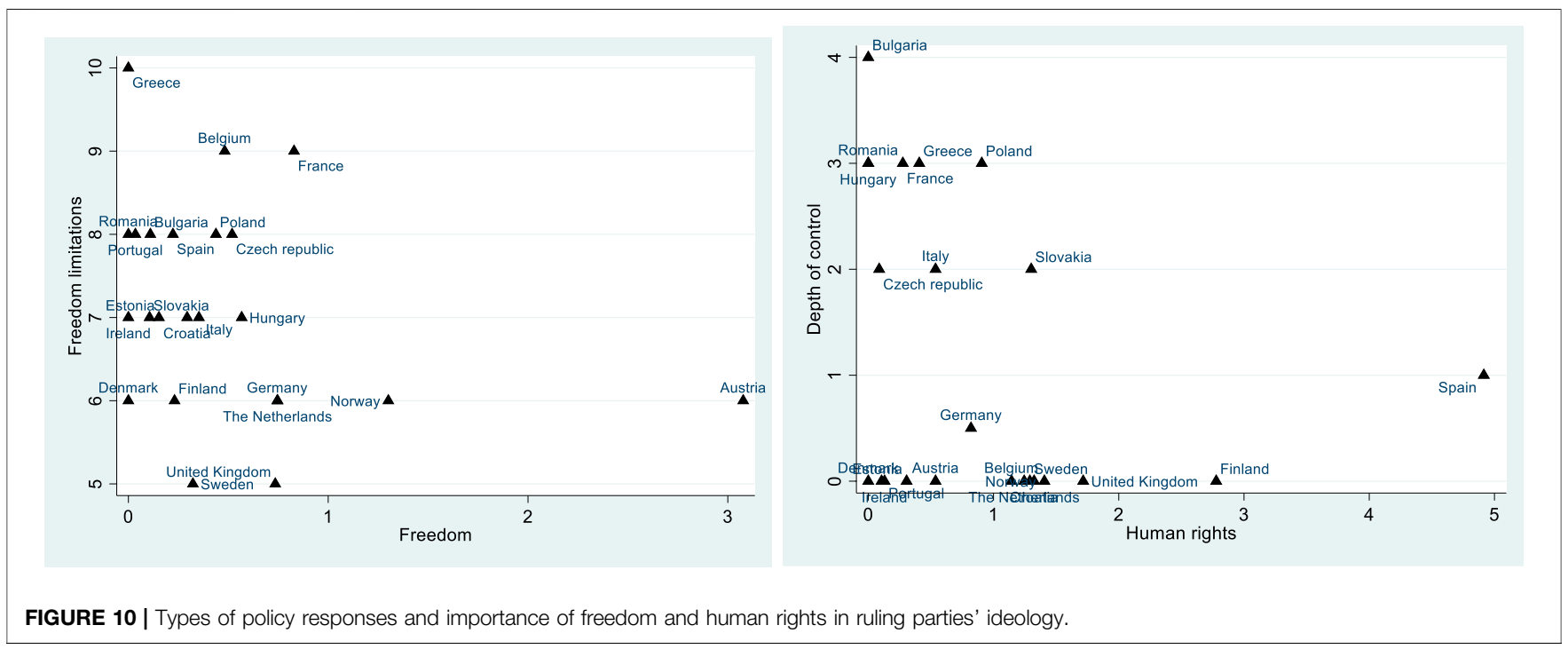

First, the idea that policy-makers face a trade-off in crisis settings receives mixed support. In our conceptual framework, a trade off leads policy-makers to arbitrate between three key elements: a) the magnitude of the threat posed not poses by the pandemic, b) the capacities they have to design various policies and c) the assumed level of compliance of the population with the measures taken. Whatever the indicator used, the characteristics of the pandemic are not associated with the level of stringency of

TABLE 1 | Summary of the results.

\section{Statistical significance level}

$5 \%$ level

Trade-off scenario

Positive cases

Deaths

ICU occupancy

Density of the population

Share of people aged 70

Health expenditure (\% GDP)

$\mathrm{N}$ hospital beds (1,000 inh.)

GDP per capita

Levels of indebtedness

Trust in Gouvernement

Trust in police

Trust in other people

Satisfaction with democracy

Checks and balances scenario

$\%$ Seats in parliament

Political contraints (polcon 5)

State of emergency

Ideological scenario

Consecutive years under democracy

Past democratic breakdowns

Promoting personal freedom (manifestos)

Promoting human and civil rights

Promoting democracy

Promoting strong government

Promoting strict law enforcement

Promoting military crisis-management policies. The pace of the contagion, number of deaths, size of the vulnerable population or population density are not correlated with the measures taken. This suggests that policymakers do not fully consider the available epidemiological data in the design of their policies. However, this result does not mean that the severity of the pandemic is an irrelevant driver of policy responses. First, risk perception matters and can be differently assessed by governments based on, for example, the historical experience of a country. Second, the adoption of a time series design - that our data do not allow-would have likely revealed that stringent measures are implemented when deaths dramatically increase or when the hospitals are full. What our results simply suggest is that the initial levels of stringency and intrusiveness of policy responses are not associated with the absolute level magnitude of the pandemic. Similarly, regarding the capacity of treating patients, only the healthcare expenditures as a share of the GDP are negatively associated with restrictions, but more accurate measures-such as the share of hospital beds-do not confirm this finding. Regarding the overall state capacity, results are mixed. Many debates revolve around the impact of state's indebtedness on their capacity to face crisis, but we only find a relationship between the debt as a share of GDP and the level of freedom limitations. On the other hand, GDP per capita is strongly and negatively associated with all the restrictions. Finally, trust, whatever the indicator used, is also clearly correlated with the restrictions. It is difficult, however, to identify a clear scenario because trust, in turn, is also strongly correlated with the GDP per capita and with the level of healthcare expenditures. At this stage, our data do not fully support the tradeoff scenario. However, we can conclude that long-term structural variables, such as wealth or trust, are more relevant to explain cross national variation in pandemic policy-making than conjectural factors, like the evolution of the pandemic or the capacities of the hospitals to treat respiratory emergencies. Moreover, this result is confirmed for both indicators of restrictions, freedom limitations but also the depth of control relied upon to enforce the measures. 
The second scenario put forward by our analytical model claims that policy-makers are constrained in the policy options they can select, because of the control of counter-powers. Our results do not confirm that counter-powers are particularly suspicious of the action of the executive in crisis times. Interestingly, however, while our different measures of check and balances do not predict freedom limitations, they all predict the depth of control used. As noted, this difference is particularly due to a specific case, Belgium, in which the executive power is the weakest in the Europe Union. It is also one of the two countries-with Portugal-where the limitations are stringent, but the control not stronger. This specific case suggests that an alternative mechanism may be at stake. Check and balances protect citizens against abuses in the enforcement of the measures, but not against the decision of implementing very stringent ones. Pandemics, as other crises, seem to trigger a rally around the flag effect leadings all political stakeholders to support the action of the executive, at least in the early stages of a crisis. The likelihood of declaring a state of emergency is not higher when the counter-powers are weak. However, the powers of the police or of the army increase less when counter powers are strong, even under state of emergency. At this stage, however, we cannot confirm this result that could be a simple statistical artefact. Moreover, it must be noted that our indicators of checks and balances, while not correlated with each other, are both associated with GDP per capita and, therefore, spurious causality is highly probable.

Lastly, our results suggest that the political preferences of the rulers play an ambiguous role in crisis response. On the one hand, countries having a long democratic experience are less likely to implement stricter restrictions in freedoms than the others are. This could be associated with a lower appeal for authoritarian rule, especially among the politicians. On the other hand, the differences in political manifestos among the rulers of different countries are not clearly associated with the level of restrictions adopted. Whether they explicitly support freedom, democracy and human rights or rather privilege order, authorities or the army, ruling parties' ideologies do not strongly shape crisis management policies, even though some significant relationships can be found with a party's emphasis on freedom and human rights. Again, as in the previous scenarios, structural drivers seem to better explain the restrictions than the specific situation in which the country faces the pandemic.

All in all, none of our scenarios are clearly supported, but our results draw some directions for further research. First, our initial findings systematically contradict the idea that pandemicmanagement policies are associated with the situational sanitary situation of a country. The severity of pandemic, the number of beds, the number of vulnerable people, the level of indebtedness and the ideology of the party in charge are weakly or not associated with the severity of the measures taken. In contrast, long-term structural factors are much more predictive: the level of interpersonal and political trust, the GDP per capita, the democratic experience and, partly, the existence of counterpowers are all associated with restrictive policies. While our results do not allow identifying which of these causes are the most explanatory ones, answers have to be found among these inheritances of the past, be they political culture, institutions or the state of the economy. Our limited sample size and the use of crosssectional data do not allow to draw any meaningful generalization from our results. Yet, these preliminary analyses nonetheless inform the analysis of crisis policy-making. First, our results call for collecting more fine grained data not only on the types of exceptional measures adopted in the wake of a crisis but also on the range and coerciveness of the modalities used to enforce them. Second, they shed new light on the nature and challenges of supranational coordination in crisis management at the EU level. The fact that the timely activation of coordinated crisismanagement mechanisms did not prevent member states from opting for their own course of action does not mean that EU governments did not cooperate or emulate each other. Our data for example reveal that close countries characterized by shared political experiences and history-such as the Nordic countries or the Eastern European ones-followed a very close course of action. When compared with the United States or Canada, crisismanagement capacities at the EU level are far more restricted. The interconnectedness of EU members states is also likely to trigger policy coordination among EU subnational regions and cities, a pattern our data do not allow to grasp so far. Given the importance our results give to such capacities in shaping policy responses, our analysis calls for further strengthening fiscal and budgetary solidarity among member states if more coordination is to be achieved at the EU level for future crises. To answer these questions in a more fine grained manner and further develop the potential of our data we have started a project mapping the modalities of exceptional decision-making in all the subnational regions of the European Economic Area. We especially intend to collect data on seven dimensions of political exceptionalism ${ }^{3}$ covering both the decision taken and their enforcement mechanisms based on a combination of automated and manual coding of policy decisions ${ }^{4}$. We expect these data to further allow unpacking how governments respond to crises and how each of the factors of our theoretical framework influences different types of measures. For each event, the emergency instrument used [both at the national and subnational (regional) level], its coverage, target groups as well as its degree of implementation (degree of constraints, enforcement mechanisms such as fines, jail sentences...) are identified. We expect such data to allow to better understand the impacts and determinants of political exceptionalism in a context where societies are increasingly exposed to various types of crises.

\footnotetext{
${ }^{3}$ The identified dimensions are 1. State of emergency (SE): democratic governance and check and balances under crisis contexts (e.g., suspension of parliamentary sessions, or local powers); 2. Restrictions of fundamental rights and civil liberties (e.g., freedom of movement, speech or press); 3. Legal restrictions of daily liberties (e.g., wearing masks, COVID10 tracking app or quarantines); 4. Closures/ lockdown (e.g., closing schools or ban public events); 5. Suspension of international cooperation and commitments (e.g., including suspensions of visa delivery or closing embassies); 6. Police mobilization (e.g., transportation, federal, local police and their size): 7. Army mobilization (e.g., deployment in the street or in border or public and private buildings).

${ }^{4}$ For more information on the project, please visit https://exceptius.com/
} 


\section{DATA AVAILABILITY STATEMENT}

The raw data supporting the conclusions of this article will be made available by the authors, without undue reservation.

\section{AUTHOR CONTRIBUTIONS}

CE: Paper framing, theoretical framework, data collection and analysis, mansucript writing, review and finalisation. RMB: theoretical framework, data collection and analysis, manuscript

\section{REFERENCES}

Alemayehu, D., and Doksum, K. (1990). Using the bootstrap in correlation analysis, with application to a longitudinal data set. J. Appl. Stat. 17 (3), 357-368. doi:10.1080/02664769000000008

Allison, G. T., and Zelikow, P. (1971). Essence of decision: explaining the Cuban missile crisis, vol. 327. Boston: Little, 729., no. 1Brown 1971.

Bjørnskov, C., and Voigt, S. (2018a). The architecture of emergency constitutions. Int. J. Constitut. L. 16 (1), 101-127. doi:10.1093/icon/moy012

Bjørnskov, C., and Voigt, S. (2020). This time is different? On the use of emergency measures during the Corona pandemic No. 36. ILE Working Paper Series.

Bjørnskov, C., and Voigt, S. (2018b). Why do governments call a state of emergency? On the determinants of using emergency constitutions. Eur. J. Polit. Economy 54, 110-123. doi:10.2139/ssrn.2988014

Boix, C., Miller, M., and Rosato, S. (2012). A complete data set of political regimes, 1800-2007. Comp. Polit. Stud. 46 (12), 1523-1554. doi:10.1177/0010414012463905

Bolsover, G. (2020). Balancing freedoms, rights and responsibilities during COVID in US: a study of anti-and pro-restriction discourse. SSRN Electron. J. 14, 33 doi:10.2139/ssrn. 3678626

Burns, C., Clifton, J., and Quaglia, L. (2018). Explaining policy change in the EU: financial reform after the crisis. J. Eur. Public Pol. 25 (5), 728-746. doi:10.1080/ 13501763.2017.1301535

Butkiewicz, J. L., and Yanikkaya, H. (2006). Institutional quality and economic growth: maintenance of the rule of law or democratic institutions, or both? Econ. Model. 23 (4), 648-661. doi:10.1016/j.econmod.2006.03.004

Capano, G., Howlett, M., Darryl, S., Jarvis, L., Ramesh, M., and Goyal, N. (2020) Mobilizing policy (In)Capacity to fight COVID-19: understanding variations in state responses. Pol. Soc. 39 (3), 285-308. doi:10.1080/ 14494035.2020 .1787628

Cheng, C., Barceló, J., Hartnett, A. S., Kubinec, R., and Messerschmidt, L. (2020) COVID-19 government response event dataset (CoronaNet v.1.0). Nat. Hum. Behav. 4 (7), 756-768. doi:10.1038/s41562-020-0909-7

De Groot, J. I. M., Schuitema, G., and Schuitema, Geertje. (2012). How to make the unpopular popular? Policy characteristics, social norms and the acceptability of environmental policies. Environ. Sci. Pol. 19-20, 100-107. doi:10.1016/j.envsci. 2012.03.004

Desvars-Larrive, A., Dervic, E., Haug, N., Niederkrotenthaler, T., Chen, J., Di Natale, A., et al. (2020). A structured open dataset of government interventions in response to COVID-19. Sci. Data. 12, 47. doi:10.37473/dac/10.1101/2020.04. 14.20065318

Dollar, D., and Kraay, A. (2003). Institutions, trade, and growth. J. Monetary Econ. 50 (1), 133-162. doi:10.1016/s0304-3932(02)00206-4

Dong, E., Du, H., and Gardner, L. (2020). An interactive web-based dashboard to track COVID-19 in real time. Lancet Infect. Dis. 20 (5), 533-534. doi:10.1016/ s1473-3099(20)30120-1

Drinóczi, T., and Bień-Kacała, A. (2020). COVID-19 in Hungary and Poland: extraordinary situation and illiberal constitutionalism. Theor. Pract. Legis. 14, 1-22. doi:10.1080/20508840.2020.1782109

European Commission. (2020a). European civil protection and humanitarian aid operations, what we do Civil protection (consulted on September 18th). New writing and review. SR: data collection on dependent variable, manuscript review and section on methods. KA: theoretical argument on trust, article review.

\section{FUNDING}

This project has benefitted from the generous support of the ZonMw Netherlands Organization for Health Research and Development (ZonMw, project nummer: 10430032010026) and of the University Grenoble Alpes.

York, NY: EU Health Policy. Available at: https://ec.europa.eu/echo/what/civilprotection/mechanism_en.

European Commission. (2020b). Health systems coordination. New York, NY: EU Health Policy. Available at: https://ec.europa.eu/health/policies/systems_en.

European Council. (2020). "COVID-19: the EU's response in the field of public health", Policies , COVID-19 coronavirus pandemic (Consulted on September 26th 2020). New York, NY: EU Health Policy. Available at: https://www. consilium.europa.eu/en/policies/coronavirus/covid-19-public-health/.

Eurostat. (2020). "Debt by quarter". New York, NY: EU Health Policy. Available at: https://appsso.eurostat.ec.europa.eu/nui/show.do?dataset=gov_10q_ggdebt\&lang=en.

Freitag, M., and Bühlmann, M. (2009). Crafting trust. Comp. Polit. Stud. 42 (12), 1537-1566. doi:10.1177/0010414009332151

Gibson, J. L. (1989). Understandings of justice: institutional legitimacy, procedural justice, and political tolerance. L. Soc. Rev. 23, 469-496. doi:10.2307/3053830

G. Capano, M. Howlett, and M. Ramesh (2015). Varieties of governance: dynamics, strategies, capacities. Berlin: Springer.

Hale, T., Noam, A., Emily, C.-B., Laura, H., Beatriz, K., Saptarshi, M., et al. (2020b). Oxford COVID-19 government response tracker. Blavatnik: Blavatnik School of Government.

Hale, T., Petherick, A., Phillips, T., and Webster, S. (2020a). Variation in government responses to COVID-19. Blavatnik: Blavatnik School of Government.

Henisz, W. J., and Mansfield, E. D. (2006). Votes and vetoes: the political determinants of commercial openness. Int. Stud. Q 50 (1), 189-212. doi:10. 1111/j.1468-2478.2006.00398.x

Janis, I. L. (1989). Crucial decisions: leadership in policymaking and crisis management. New York, NY: Simon \& Schuster.

van Ham, J. A., Thomassen, C., Aarts, K., and Andeweg, R. B. (2017). Myth and reality of the legitimacy crisis: explaining trends and cross-national differences in established democracies. Editor van Ham, J. A. (Oxford: Oxford University Press).

Jordana, J., and Triviño-Salazar, J. C. (2020). Where are the ECDC and the EUwide responses in the COVID-19 pandemic? The Lancet 395, 1611-1612. doi:10.1016/s0140-6736(20)31132-6

Kam, E. (1988). Surprise attack. Cambridge, MA: Harvard University Press.

Kehinde, B. (2014). "Applicability of risk transfer tools to manage loss and damage from slow-onset climatic risks-11th September 2014," in Procedia economics and finance, 4 th international conference on building resilience, incorporating the 3rd annual conference of the ANDROID disaster resilience network, vol. 18. UK: Salford Quays, 8710-8717.

Keman, H. (2002). Policy-making capacities of European,Müller-rommel ferdinand and Kurt richard luther Political parties in the new Europe: Political and analytical challenges. Oxford: OUP

Krause, W., Lehmann, P., Lewandowski, J., Matthieß, T., Nicolas, M., Regel, S., et al. (2020). Manifesto corpus. Version: 2020. Berlin: WZB Berlin Social Science Center.

Landa, D., and Tyson, S. A. (2017). Coercive leadership. Am. J. Polit. Sci. 61 (3), 559-574. doi:10.1111/ajps.12303

Lau, H., Khosrawipour, V., Kocbach, P., Mikolajczyk, A., Ichii, H., Schubert, J., et al. (2020). Internationally lost COVID-19 cases. J. Microbiol. Immunol. Infect. 14, 33-39. doi:10.37473/dac/10.1101/2020.06.08.20050559

MacIntyre, A. (2001). Institutions and investors: the politics of the economic crisis in Southeast Asia. Int. Org. 55, 81-122. doi:10.1162/002081801551423 
Marto, R., Papageorgiou, C., and Klyuev, V. (2018). Building resilience to natural disasters: an application to small developing states. J. Dev. Econ. 135, 574-586. doi:10.1016/j.jdeveco.2018.08.008

McMenamin, I., Breen, M., and Muñoz-Portillo, J. (2020). Italian debt and Covid19: how do financial markets diagnose Europe's underlying condition? LSE Blog 23, 191. doi:10.5089/9781589066236.071

Morlino, L. (2010). Authoritarian legacies, politics of the past and the quality of democracy in southern Europe: open conclusions. South Eur. Soc. Polit. 15, 507-529. doi:10.1080/13608746.2010.513609

OECD. (2020). Health spending (indicator). (Accessed September 18, 2020). doi:10.1787/8643de7e-en

Pickett, K., and Wilkinson, R. (2010). The spirit level: why equality is better for everyone. London: Penguin UK.

Posner, E.A, and Vermeule, A. (2003). Accommodating emergencies. StanLRev. 56 (3), 605-644.

Ritchie, H. (2020). Coronavirus Source Data, our world in data. Oxford: University of Oxford. Available at https://ourworldindata.org/coronavirus-source-data.

Roché, S., Jan, T., de Maillard, J., and Salet, R. (2020). Policing the Corona crisis. A comparison between France and The Netherlands. Int. J. police Sci. Manag. 7, 181. doi: $10.1177 / 1461355720980772$

Rothstein, B. (2012). Political legitimacy for public. Thousand Oaks, CA: The SAGE Handbook of Public Administration, 407-419.

Schneider, S., Becker, S., Boettcher, B., Heymann, E., and Schattenberg, M. (2020). COVID-19: crisis resilience made in Germany, Singapore: Deutsche bank Research.

Schneider, A., and Ingram, H. (1990). Behavioral assumptions of policy tools J.Politics 52 (2), 510-529. doi:10.2307/2131904

Staupe-Delgado, R. (2019). Progress, traditions and future directions in research on disasters involving slow-onset hazards. DPM 28 (5), 623-635. doi:10.1108/ dpm-11-2018-0358

Teorell, J., Dahlberg, S., Holmberg, S., Natalia Alvarado, P., and Axelsson, S. (2020). The quality of government standard dataset, version Jan20. Gothenburg; University of Gothenburg: The Quality of Government Institute.

Turner, B. A. (1978). Man-made disasters. London: Wykeham.

Viboud, C., Grais, R. F., Lafont, B. A. P., Miller, M. A., and Simonsen, L. (2005) Multinational impact of the 1968 Hong Kong influenza pandemic: evidence for a smoldering pandemic. I. Infect. Dis. 192 (2), 233-248. doi:10.1086/ 431150

Welch, D. A. (1989). Crisis decision making reconsidered. J. Conflict Resolution Dev.

Welch, S. (2016). The concept of political culture. Berlin: Springer.

Weymouth, S. (2011). Political institutions and property rights: veto players and foreign exchange commitments in 127 countries. Comp. Polit. Stud. 44, 211-240. doi:10.1177/0010414010382629

WHO (2020). Coronavirus disease (COVID-19) pandemic)", Health topics, health emergencies, Coronavirus disease (COVID-19) outbreak. Available at: https://www.euro.who.int/en/health-topics/healthemergencies/coronavirus-covid-19/novel-coronavirus-2019-ncov.

Wilensky, H. L. (1967). Organizational intelligence: Knowledge and policy in government and industry. New York: Free Press.

World Bank. (2020). World development indicators. Available at: https://databank. worldbank.org/source/world-development-indicators (Accessed September 10, 2020).

Zhou, L., Wu, X., Xu, Z., and Fujita, H. (2018). Emergency decision making for natural disasters: an overview. Int. J. Disaster Risk Reduct. 27, 567-576. doi:10. 1016/j.ijdrr.2017.09.037

Zmerli, S., Newton, K., and Montero, J. R. (2007). Trust in people, confidence in political institutions, and satisfaction with democracy. Citiz. Involve. Eur. Democr. Comp. Anal. 17, 35-65. doi:10.4324/9780203965757-10

Conflict of Interest: The authors declare that the research was conducted in the absence of any commercial or financial relationships that could be construed as a potential conflict of interest.

Copyright (C) 2021 Egger, Magni-Berton, Roché and Aarts. This is an open-access article distributed under the terms of the Creative Commons Attribution License (CC $B Y$ ). The use, distribution or reproduction in other forums is permitted, provided the original author(s) and the copyright owner(s) are credited and that the original publication in this journal is cited, in accordance with accepted academic practice. No use, distribution or reproduction is permitted which does not comply with these terms. 
APPENDIX 1 | Descriptive statistics.

\begin{tabular}{|c|c|c|c|c|c|c|c|c|c|}
\hline Variables & Obs & Mean & Std.Dev. & Min & Max & p1 & p99 & Skew. & Kurt. \\
\hline ICU occupancy & 11 & 1.965 & 2.493 & 0 & 6.708 & 0 & 6.708 & 1.128 & 2.767 \\
\hline Health expenditure (per GDP) & 23 & 8.613 & 1.755 & 5.71 & 11.654 & 5.71 & 11.654 & 0.044 & 1.782 \\
\hline Trust in government & 19 & 2.85 & 0.265 & 2.36 & 3.39 & 2.36 & 3.39 & 0.105 & 2.392 \\
\hline Trust in police & 19 & 2.137 & 0.309 & 1.59 & 2.73 & 1.59 & 2.73 & 0.241 & 2.246 \\
\hline Political satisfaction & 19 & 5.219 & 1.097 & 2.87 & 7.3 & 2.87 & 7.3 & -0.037 & 2.753 \\
\hline Trust in others & 19 & 1.598 & 0.21 & 1.23 & 1.87 & 1.23 & 1.87 & -0.557 & 1.932 \\
\hline$\%$ seat & 23 & 0.356 & 0.14 & 0.08 & 0.668 & 0.08 & 0.668 & 0.329 & 2.708 \\
\hline Military & 23 & 2.429 & 2.266 & -0.737 & 6.891 & -0.737 & 6.891 & 0.641 & 2.147 \\
\hline Freedom & 23 & 0.49 & 0.656 & 0 & 3.077 & 0 & 3.077 & 2.829 & 11.713 \\
\hline Humanrights & 23 & 0.923 & 1.12 & 0 & 4.915 & 0 & 4.915 & 2.158 & 8.177 \\
\hline Democracy & 23 & 1.924 & 2.667 & -0.036 & 12.424 & -0.036 & 12.424 & 2.899 & 11.714 \\
\hline Authority & 23 & 0.304 & 1.173 & 0 & 5.666 & 0 & 5.666 & 4.433 & 20.789 \\
\hline Order & 23 & 4.993 & 3.164 & 0.283 & 14.516 & 0.283 & 14.516 & 1.043 & 4.632 \\
\hline PDM & 21 & 0.524 & 0.814 & 0 & 3 & 0 & 3 & 1.634 & 5.228 \\
\hline CYCR & 22 & 59.818 & 40.529 & 11 & 126 & 11 & 126 & 0.32 & 1.481 \\
\hline Polcon5 & 22 & 0.747 & 0.134 & 0.226 & 0.893 & 0.226 & 0.893 & -2.91 & 11.888 \\
\hline Freedom limitations & 23 & 7.043 & 1.107 & 5 & 9 & 5 & 9 & -0.292 & 2.031 \\
\hline Depth of control & 23 & 1.152 & 1.41 & 0 & 4 & 0 & 4 & 0.628 & 1.768 \\
\hline GDP per capita & 23 & $36,230.28$ & $19,810.22$ & $9,737.601$ & $78,660.96$ & $9,737.601$ & $78,660.96$ & 0.543 & 2.374 \\
\hline Debt per gdp & 23 & 0 & 0 & 0 & 0 & 0 & 0 & 0.618 & 2.843 \\
\hline Contagion & 23 & $9,806.304$ & $18,224.23$ & 196 & 75,641 & 196 & 75,641 & 2.781 & 9.705 \\
\hline Deaths & 23 & $2,798.435$ & $4,462.216$ & 28 & 15,238 & 28 & 15,238 & 1.73 & 4.706 \\
\hline Population density & 23 & 135.622 & 117.853 & 14.462 & 508.544 & 14.462 & 508.544 & 1.773 & 5.886 \\
\hline Aged_70 & 23 & 12.716 & 1.882 & 8.678 & 16.24 & 8.678 & 16.24 & -0.271 & 2.969 \\
\hline Hospital beds & 23 & 4.862 & 1.885 & 2.22 & 8 & 2.22 & 8 & 0.145 & 1.524 \\
\hline
\end{tabular}

